\title{
Teoria e aspectos prático- metodológicos na Educação Física: reforçando um método de intervenção com jovens matriculados no Ensino Médio
}

Carlos Eduardo de Souza*

Resumo: $\mathrm{O}$ artigo que se segue tem como fundamento a metodologia "histórico-crítica" e busca relatar aspectos teórico-práticos a partir das aulas que foram compartilhadas, durante dois anos, com os jovens matriculados no projeto "território de Oportunidades” da Universidade Federal de Juiz de Fora. As temáticas e as práticas relacionadas aqui se encontram de forma inacabadas e provisórias, também não tem o objetivo de fornecer uma receita, porém nos ajudam a refletir sobre o papel do professor de Educação Física inserido em um projeto distinto de sociedade.

Palavras-chave: Educação Física, Metodologia, Conhecimento.

Abstract: The following article is based on methodology "historical-critical" and seeks report from the practical lessons that were shared during two years with the youth enrolled in the project "territory Opportunities Federal University of Juiz de Fora. The themes and related practices here are so unfinished and provisional, also has the goal of providing a recipe, but help us to reflect on the role of physical education teacher entered into a project separate from society.

Keywords: Physical education, Methodology, Knowledge.

* Mestrando no programa de Pós-Graduação em Educação da Universidade Federal de Juiz de Fora (PPGE/UFJF). E-mail: kadusjn@yahoo.com.br 


\section{Trabalho, educação e homem}

Um pressuposto para a caracterização e análise do ser humano, portanto indispensável para apreensão teórica, é que a essência do homem se encontra no fato de que esse precisa adaptar a natureza a si, agindo sobre ela e transformando-a para que se mantenha de pé. Nesse sentido o homem também sofre alterações. Tratase, portanto, de uma relação dialética. Ao fazer isso o homem acaba por produzir trabalho. Para Marx (1985) esse é o fato que distingue os homens do restante dos animais, observa-se dai a capacidade de projeção e racionalização da mente humana. Marx, ao explicar a dimensão ontológica do trabalho humano, faz a seguinte comparação:

Uma aranha executa operações semelhantes às do tecelão, e a abelha envergonha mais de um arquiteto humano com a construção dos favos de suas colméias. Mas o que distingue, de antemão, o pior arquiteto da melhor abelha é que ele construiu o favo em sua cabeça, antes de construí-lo em cera. No fim do processo de trabalho obtém-se um resultado que já no início deste existiu na imaginação do trabalhador, e, portanto, idealmente. Ele não apenas efetua uma transformação da forma da matéria natural: realiza, ao mesmo tempo, na matéria natural seu objetivo, que ele sabe que determina como lei, a espécie e o modo de sua atividade e ao qual tem de subordinar sua vontade (MARX, 1985, p. 149-150).

Segundo Saviani (1997), ao produzir continuamente a sua existência através do trabalho, o homem necessita se educar, sendo a educação uma exigência do e para o processo de trabalho, e ela própria se constitui em trabalho.

Se fecharmos os olhos e os abrirmos em seguida, nós nos deparamos com a própria educação, pois esta se materializa no diverso como um todo (cultura), sendo algo que se dá no contato imediato e na manipulação da natureza fazendo a mediação entre o passado e o futuro.

Portanto, para entender o homem e as relações sociais que ele estabelece ao longo da história torna-se necessário compreender a centralidade do trabalho e a realidade que nos cerca. Sendo assim, 
podemos nos indagar: como o trabalho vem sendo caracterizado tendo como base o modo de produção capitalista?

Ainda segundo Marx (1985), quando o homem toma para si os meios de produção, criam-se contraditoriamente duas classes sociais, a dos que detêm os meios de produção e a daqueles que necessitam vender o único bem que lhes restou, sua força de trabalho. Dentro dessa relação, o trabalho toma um aspecto negativo e se torna um meio de vida, onde seu produto fica estranhado do produtor. Soma-se a isso a divisão do trabalho em esferas exclusivas e determinadas para cada trabalhador, levando-o à não compreensão da totalidade de seu trabalho, não permitindo que o homem desenvolva suas várias dimensões humanas, assemelhando-se à abelha e à aranha. Tudo isso confere o aspecto destrutivo do ser ontológico. Segundo Marx e Engels (1989, p. 29), nesse modo de produção, "o homem é caçador, pescador, pastor ou crítico e deverá permanecer assim se não quiser perder seus meios de sobrevivência".

Se é pelo trabalho que o homem constrói a sua humanidade e é através da educação que se busca transmitir para cada indivíduo singular a humanidade construída pelo conjunto dos homens, cabe aqui uma segunda indagação: Que humanidade está sendo construída tendo em vista os aspectos (negativos) que o trabalho assume em uma sociedade de classe? Nesse mesmo cenário, quais aspectos mediadores a educação assume?

Segundo Saviani (1997), o ensino formal surge no contexto, em que os donos dos meios de produção tinham que ocupar seu tempo livre, sendo uma forma de educação secundária, já que a maioria da população se educava pelo trabalho. Dadas as condições de vida na cidade, a partir da revolução industrial, necessitou-se universalizar o acesso à educação básica, tornando-se a escola a instituição principal de transmissão/assimilação do conhecimento.

No modo de produção capitalista, o saber produzido pela ação dos homens sobre a natureza tende a se tornar uma força produtiva, sendo, portanto propriedade da classe dominante, que deve oferecer ao trabalhador apenas o mínimo para que ele possa produzir (SAVIANI, 1997). 
Trazendo a discussão da educação para suas aparições contemporâneas, é necessário dizer que historicamente o capital passou por constantes mudanças no seu processo de produção, iremos nos ater nesse momento no processo produtivo que se hegemonizou a partir da crise do estado de bem-estar social, crise esta que se caracterizou pela saturação de mercados internos, pela crise fiscal inflacionária e pela defesa da volta das leis naturais do mercado, abrindo campo para o advento do neoliberalismo enquanto política de contenção da crise do capital, centrando ataques fundamentalmente às conquistas sociais trabalhistas (ANDERSON, 1995). Mais amplamente, o advento do neoliberalismo sugere nova sociabilidade, por isso torna a educação um campo fecundo de inculcação ideológica.

Nesse processo produtivo conhecido como toyotismo, observamos a constituição de formas de acumulação flexível, das formas de gestão organizacional, do avanço tecnológico, que apresenta uma produção vinculada à demanda com vistas a atender as exigências do mercado consumidor, com uma produção variada e bastante heterogênea, o trabalho operário em equipe, com um trabalhador polivalente, o princípio do just in time, com melhor aproveitamento possível do tempo de produção e estrutura horizontalizada da produção (ANTUNES, 1999).

Nesse contexto, a educação deve servir na formação do novo tipo de trabalhador, ou seja, polivalente, flexível e empreendedor. Na teoria tem-se uma educação que irá fornecer as competências técnicas para o individuo se manter empregado, entretanto sabemos que a atual fase do modo de produção capitalista constrói um cenário de desemprego estrutural, sendo assim, essa formação torna-se falaciosa, pautada no discurso de culpabilização do trabalhador. Se o trabalhador não consegue se empregar é porque não tem competências ou não se interessou em obtê-las, com isso a escola mascara um projeto de educação que visa formar para o desemprego (GENTILI, 1998).

Tais diretrizes educacionais vêm se apoiando nas pautas de reinvidicações dos organismos internacionais ligados ao capital 
financeiro, num processo de globalização. Para Roberto Leher (1999), são dois os organismos fundamentais nesse processo, o Banco Mundial e o Fundo Monetário Internacional, juntos determinam aos países periféricos que persigam "boas políticas educacionais" que coincidam com as suas proposiçôes.

\section{O caráter contraditório da educação: a educação como instrumento da luta de classes}

De acordo com Frigotto (2006), a educação e a escola no sistema capitalista tendem a reproduzir os interesses da classe dominante, mas por se darem num contexto de luta de classes, de interesses antagônicos, não se limitam à reprodução e, portanto, interessam à classe trabalhadora que deve buscar evidenciar as contradições, instalar-se nelas e trabalhá-las no sentido de superálas. Adotar o espaço escolar como possibilidade de formação da classe trabalhadora significa pressionar o Estado a repensar o projeto educacional no que tange sua laicidade, gratuidade, universalidade e sua qualidade.

O Estado tenta dissimular seu caráter de classe, como sendo uma esfera autônoma capaz de refletir o consenso de toda a sociedade, no entanto, é resultado da correlação de forças originadas na sociedade civil, portanto está subordinado a uma dinâmica que advém das relações sociais existentes (MACHADO, 1989).

A política educacional implementada pelo Estado, no Brasil, materializa uma proposta de educação, com vistas a formar no trabalhador as competências básicas exigidas para o acesso ao mercado de trabalho, a empregabilidade e uma nova sociabilidade, pautada no culto à individualidade. Se partirmos do pressuposto que o modo de produção capitalista no seu atual estágio de desenvolvimento necessita compor um exército de reserva e que, portanto, o desemprego é parte da estrutura desse sistema, podemos entender melhor o que sugere a empregabilidade. 
O trabalhador ao buscar o seu ingresso no mercado de trabalho tem que se cercar das competências, mas ora, se o desemprego é estrutural não será possível que todos os trabalhadores se empreguem, nesse caso, o sistema constrói no trabalhador uma nova subjetividade, a sensação de fracasso, de insucesso e de que ficou algo por fazer. Trata-se da culpabilização da vítima.

Constatar que esse projeto não atende aos interesses da classe trabalhadora é o primeiro passo para se questionar as bases da nossa educação. Cabe à classe trabalhadora as seguintes tarefas:

1. Pressionar de forma organizada o Estado no sentido da implementação de políticas públicas educacionais de acordo com seus interesses de classe. Isso significa mais verbas para a educação que garantam a todos a gratuidade e o acesso ao ensino; autonomia diante das diferentes religióes para que o trabalhador perceba a materialidade dos fatos como um processo de construção social; acesso a bibliotecas públicas; investimentos na formação dos quadros de professores; plano de carreira docente; fortalecimento e autonomia dos sindicatos; defesa de uma educação pública estatal, que não atenda a interesses de grupos privatistas e corporativistas; financiamento público para as pesquisas; extensão e ensino como práxis do saber; conhecimento ampliado, ou seja, conhecimento sólido com base na relação do homem com a natureza e com o trabalho;

2. A formulação de um projeto político pedagógico que tenha suas bases no método de análise materialista histórico e na pedagogia histórico-crítica, contrapondo-se às teorias acríticas e crítico-reprodutivistas. Marx ao estudar a economia-politica lança bases para um projeto de educação articulado aos interesses da classe trabalhadora.

O movimento da Escola Nova, surgido em meados de 1968, desenvolveu uma nova concepção de ensino que se contrapunha à educação tradicional, e pretendia realizar uma revolução social através da escola, mas não questionava a base da produção social que dava sustentação àquele tipo de educação. Esse movimento, embora tenha conseguido alguns avanços, foi sufocado 
pela exacerbação de um regime autoritário tendo como pedagogia o tecnicismo. A partir daí as teorias crítico-reprodutivistas são elaboradas com o intuito de explicar o fracasso da Escola Nova, advogando que a cultura, a educação, se situam no plano ideológico, portanto na superestrutura, não podendo, assim, alterar as bases estruturais da sociedade.

As teorias crítico-reprodutivistas vão representar um papel importante na crítica ao regime autoritário e à pedagogia tecnicista, porém apesar de fazer a crítica do existente e explicitar seus mecanismos, não apresentam propostas de intervenção prática, e ao afirmar que as coisas são assim e não podem ser de outro modo acabam por negar as contradições no seio da sociedade e a própria história (SAVIANI, 1997).

A pedagogia histórico-crítica vai surgir a partir da necessidade de se pensar formas de atuação pedagógicas capazes de valorizar a escola como um espaço contraditório e como um instrumento importante para as camadas dominadas.

Nesse sentido a pedagogia histórico-crítica não desconsidera os fenômenos, porém esses fazem parte de um todo, estabelecendo relações de causa e conseqüência numa movimentação de totalidade. Ao considerar a totalidade das relações que se estabelecem na sociedade, bem como os desafios postos para a educação, a teoria histórico-crítica é capaz de buscar as suas bases pedagógicas no princípio educativo do trabalho, uma vez que a essência do homem se encontra no próprio trabalho.

De acordo com Saviani (1997), a pedagogia histórico-crítica se esforça para compreender a questão educacional a partir do desenvolvimento das condições materiais da existência humana no processo histórico objetivo e por isso pode se articular a uma proposta pedagógica cujo objetivo é instrumentalizar a classe trabalhadora para a superação da sociedade de classes.

Marx e Engels defendiam a educação politécnica de caráter geral, que pode desenvolver no educando e no educador a capacidade de estabelecer relações entre o todo que se produz contrapondo o à formação fragmentada dos conteúdos. Tratar-se-ia, 
portanto, do desenvolvimento humano em suas múltiplas dimensões. Frigotto (2006) afirma que o trabalho, como princípio de ontocriação do ser humano e cerne educacional, não se trata de uma técnica didática, mas sim de um pressuposto ético-político num processo de socialização humana.

Antonio Gramsci aponta para uma estrutura educacional unitária capaz de se contrapor à dualidade do ensino, ou seja, a educação enquanto práxis humana. Portanto a educação politécnica/tecnológica e a escola unitária são compreendidas, nessa ordem, como a síntese superadora dos limites da divisão do trabalho e a capacidade de integrar o conhecimento intelectual, clássico, instrumental e profissional.

Essa formação contra hegemônica, agregada com a organização dos trabalhadores em torno de seus interesses, constrói as bases que poderá dar ao homem sua capacidade crítica assim como o desenvolvimento de suas plenas faculdades físicas e intelectuais.

\section{Trabalho, educação e Educação Física:}

A partir do século XIX, com a Revolução Industrial o trabalho passa a ser organizado de maneira mais sistemática dentro das fábricas, explicitando uma delimitação mais nítida entre tempo de trabalho e tempo de não-trabalho. $\mathrm{O}$ tempo de nãotrabalho, ou "tempo livre" era o momento que o trabalhador se encontrava livre das obrigações fabris e preencher esse tempo de forma a melhorar o rendimento dos trabalhadores para o trabalho produtivo e ajudar na conformação ideológica para uma melhor extração da mais valia, se tornava latente e deveria abarcar valores e concepçôes de mundo próprias de uma burguesia emergente.

Nesse contexto a Educação Física ganha força, seja como prática voltada para a distração da classe trabalhadora, seja para a revitalização da força de trabalho, seja para a disseminação de idéias e valores próprios da classe burguesa. 
No Brasil, segundo Soares (1994), as preocupações com a educação do corpo dos indivíduos surgem ainda no período colonial, justificadas pelos altos índices de mortalidade infantil e pelas condições precárias de saúde dos adultos, mas tendo como locus de atuação as famílias das elites e a busca pela superioridade da classe dominante e da raça branca, influenciados pelo pensamento eugenista e higienista.

Com o advento da República e o crescente processo de industrialização e urbanização o pensamento higienista ganha cada vez mais força, pois aparecia como possibilidade de assepsia do corpo, educação moral e preparação do trabalhador saudável.

As condições de vida na cidade e de trabalho nas fábricas eram cada vez mais degradantes e o discurso hegemônico buscava responsabilizar o trabalhador pela busca da sua saúde, através da adoção de hábitos higiênicos, da prática de atividades físicas, sem, no entanto, alterar as suas condições de trabalho e de vida.

O higienismo buscava resolver o problema da saúde que advém de uma conjuntura caótica, de uma nação de industrialização nascente e de urbanização não planejada, através do discurso da educação, no qual a educação física ganha centralidade: Era preciso adestrar o corpo do trabalhador, desenvolver seu vigor físico e discipliná-lo, para sua função na produção e reprodução do capital (SOARES, 1994; GHIRALDELLI, 1992).

A ginástica, principalmente influenciada pelas escolas francesa e sueca, se torna a forma preponderante dentro dessa concepção de educação física.

No período entre guerras, o foco da saúde deixa de estar no indivíduo como no discurso médico-higienista e a pátria passa a ser o objetivo central, sendo assim a disciplina, a hierarquia, a obediência e o respeito, passam a servir de base para a educação da nação, nesse momento mais uma vez a Educação Física torna-se estratégica para a conformação desses valores e a elevação da nação.

Após a II Guerra Mundial, surge a preocupação em conformar a Educação Física como disciplina curricular e o esporte passa a ser seu conteúdo principal, passando a escola a ser uma 
extensão da instituição esportiva e reprodutora de seus princípios como competição, comparação de rendimentos e recordes, regulamentação rígida, sucesso no esporte como sinônimo de vitória, racionalização de meios e técnicas, que podem ser resumidos nas competências da racionalidade, eficiência e produtividade (COLETIVO DE AUTORES, 1992).

Apesar das especificidades assumidas pela Educação Física em cada período histórico analisado, ela sempre esteve apoiada no discurso de pensadores liberais, o positivismo, a concepção a-histórica de homem, a ênfase no corpo biologizado conferiam a essa disciplina um caráter mecanicista e utilitarista a serviço do pensamento dominante (SOARES, 1994).

Pensar a educação física para a classe trabalhadora compreende resgatarmos as teorias criticas, as manifestações culturais, as produções científicas dentro do processo de abertura política e de redemocratização da sociedade brasileira. A década de 1980, dentro da educação física, esteve marcada por diversos autores que buscavam no pensamento e na filosofia marxista respostas para a superação da sociedade de classes.

Em 1992, reúnem-se seis professores, Valter Bracht, Celi Neuza Zulke Taffarel, Lino Castellani Filho, Micheli Ortega Escobar, Carmem Lúcia Soares e Elizabeth Varjal, com o objetivo de sistematizar uma proposta metodológica de ensino da Educação Física comprometida com a classe trabalhadora que buscou sintetizar o debate entre a "aptidão física" e "reflexão sobre cultura corporal $^{1}$ fazendo o leitor refletir sobre o projeto político pedagógico, concepção de currículo ampliado, trato com o conhecimento, ciclos de escolarização, tematização e estrutura das aulas,

\footnotetext{
Educação Física dentro dessa perspectiva deve ser compreendida enquanto prática pedagógica que trata do conjunto das manifestaçóes corporais produzidas pelos seres humanos ao longo da história, ou seja, o esporte, a ginástica, o jogo, as lutas e a dança. Essas práticas, portanto, constituem a chamada cultura corporal de movimento Essa inspiração teórica fundamenta-se na proposta crítico-superadora que aborda os conteúdos da cultura corporal de movimento na sua totalidade, ou seja, sob o enfoque de diversas áreas e ciências (biologia, sociologia, história, etc), naquilo que lhes são específicos (técnicas, táticas, regras) e nas implicaçôes com o mundo e a realidade social. (COLETIVO DE AUTORES, 1992).
} 
resgate histórico dos fundamentos que vêm legitimando a educação física, apresentando uma nova forma de apreensão de seu conteúdo e um novo sentido na avaliação do aluno.

No que tange o projeto político-pedagógico, devemos constatar que ele irá nortear a prática do educador no interior da escola, temos que ter claro que não é algo neutro, pelo contrário, reflete a visão de mundo de quem o organiza, por isso é político. Sendo assim, interessa aos trabalhadores buscar no projeto político pedagógico os caminhos que irão conduzi-los aos seus interesses de classe.

O currículo ampliado em Educação Física deverá ser capaz de possibilitar ao aluno pensar a realidade social complexa e contraditória, portanto deverá ter como objetivo a compreensão da totalidade dos fatos levando os alunos refletirem sobre a essência de seus problemas no sentido de superá-los coletivamente. As relações que o homem estabelece com a natureza, com a sociedade, com o trabalho e com a própria educação deverão ser pontos de apoios para a construção do conhecimento. Esse por sua vez deverá ser "diagnóstico, judicativo e teleológico", ou seja, o aluno deverá, a partir do conhecimento adquirido, ser capaz de constatar, interpretar e explicar a realidade social concreta para que enfim possa projetar seus interesses (SOUZA apud COLETIVO DE AUTORES, 1987).

Os conteúdos a serem trabalhados nas aulas de Educação Física devem ser selecionados de acordo com sua relevância no sentido de instrumentalizar o aluno para os enfrentamentos da sua realidade. Devem ainda, ser contemporâneos e adequados às possibilidades cognoscitivas dos alunos. Os conhecimentos devem ser assimilados de forma espiralada, e compreendidos como dados simultâneos da realidade, superando a visão fragmentada da mesma, e entendidos como provisórios, para que o aluno se perceba enquanto sujeito histórico (COLETIVO DE AUTORES, 1992).

Se retomarmos todo o texto até aqui escrito para refrescarmos nossa mente em relação à temática tratada, o leitor poderá lembrar: 1 - o trabalho, por compor a essência do homem, torna-se 
central para o entendimento das relações sociais; 2 - os trabalhadores devem estar atentos a seus interesses cabendo a eles tarefas de classe; 3 - a formulação de políticas públicas educacionais que garantam laicidade, gratuidade, qualidade assim como um projeto político pedagógico com base na pedagogia histórico-crítica e o método materialista histórico tornam-se imprescindíveis para a classe trabalhadora; 4 - a Educação Física é algo conflitante e permeado de interesses sociais e que, portanto, não está à margem da luta de classes.

Em suma, o Coletivo de Autores (1992) nos traz grandes contribuições teóricas que nos ajuda pensar uma nova Educação Física, assim como uma nova sociedade já que o seu objetivo real está na superação das classes sociais, portanto, mesmo produzido em 1992 é algo atual. Posto a não superação, ainda, do modo de produção capitalista. No entanto, o mesmo não se configura a nosso ver em uma proposta acabada, pelo contrário, abre a reflexão e nos dá possibilidades de avanços de classe. Muitos professores ao lerem o Coletivo de Autores ficam apreensivos no que tange a sua prática a partir dessa teoria.

A vivência didático-pedagógica, a partir das aulas que iremos ilustrar mais à frente, sugere aos leitores diferentes formas de trabalhar ou tematizar alguns conteúdos da "cultura corporal" e é o resultado do nosso trabalho com jovens do projeto Território de Oportunidades da Universidade Federal de Juiz de Fora.

\section{O projeto "Território de Oportunidades" e a oficina de Educação Física}

Os jovens matriculados no projeto tiveram a oportunidade de vivenciar atividades físicas que não fazem parte do seu cotidiano, além de discutir questões relacionadas a essas práticas como questões relacionadas ao gênero, construção coletiva e os valores que envolvem essa construção, importância da participação e colaboração de todos. Tiveram também a oportunidade 
a partir da "cultura corporal de movimento" de se reconhecer enquanto sujeito social e produtor de cultura, enfim, passaram por um processo de desconstrução da idéia de que a Educação Física é só um espaço de diversão, de excitação, onde não cabe a organização e a discussão, rumo a transformação social. A dificuldade que a docência encontra ao educar seus alunos de maneira crítica para "além do capital" é algo que nos preocupa. Entendemos que esse deva ser um exercício continuo de reflexão e troca de conhecimentos entre aqueles que buscam a superação dessa sociedade. Aí esta o objetivo maior desse artigo.

O Pólo de Suporte às Políticas de Proteção a família, infância e juventude da Universidade Federal de Juiz de Fora é um programa de extensão que busca, através da articulação entre a comunidade acadêmica e a sociedade, contribuir para o fortalecimento de políticas públicas, prioritariamente as de assistência social desenvolvidas na zona da mata mineira e adjacências, destinadas à família, infância e juventude e tem como estratégia de intervenção atuar em três dimensões que se expressam em três linhas de ação:

Assessoria à gestão de políticas, programas e projetos sociais destinados a família, infância e juventude;

Capacitação de recursos humanos envolvidos nas políticas, programas e projetos sociais destinados a família, infância e juventude;

Desenvolvimento de projetos de atendimento a família, infância e juventude, que possuam caráter experimental e que estejam diretamente vinculados à pesquisa e ao ensino.

E é nessa última linha de ação que surge o UFJF - Território de Oportunidades. A demanda inicial de um trabalho com jovens, foco central do projeto Território de Oportunidades dentro da UFJF, surge a partir de um fato ocorrido no campus da universidade, quando dois grupos moradores de bairros vizinhos se enfrentaram e se agrediram. A falta de oportunidades desses jovens se inserirem na vida social, em particular aqueles provenientes dos setores populares, que encontram imensas dificuldades em dar continuidade a seus estudos, de inserção no mercado de trabalho, de escapar de grandes períodos de desemprego, mais o risco desses alunos se envolverem com drogas, com crime organizado 
e com outras formas de exploração e abuso hoje tão correntes são outros fatores que apontam para essa demanda.

O projeto reuniu jovens, de 15 a 18 anos, matriculados e freqüentadores do Ensino Médio, residentes nos bairros São Pedro e Dom Bosco, que circundam a Universidade Federal de Juiz de Fora.

Essa primeira turma teve a duração de dois anos, sendo iniciada em março de 2005 e finalizada em dezembro de 2006. Participaram inicialmente, 29 jovens ocupados em oito oficinas diferentes. A escolha dessas atividades deu-se a partir de uma compreensão das necessidades de inserção dos jovens na contemporaneidade. Sendo assim elas puderam ser divididas em três grupos:

No $1^{\circ}$ grupo ficaram as oficinas de língua estrangeira e informática que deram aos jovens a oportunidade de acesso a ferramentas e linguagens indispensáveis no mundo de hoje e, via de regra, não disponíveis, ou apenas precariamente, para os jovens filhos dos trabalhadores;

O $2^{\circ}$ grupo foi composto pelas atividades que propiciaram o acesso à cultura e aos bens simbólicos socialmente produzidos e apropriados de forma desigual. Foram as atividades do Fórum de Cultura, o Ciclo de Cinema e o Programa de Rádio;

No $3^{\circ}$ grupo ficaram reunidas as atividades que articulam a cultura e o corpo de maneira mais direta. Nele estão as oficinas de Capoeira e a Educação Física.

Ainda que realizadas separadamente essas oficinas têm sua unidade construída através de um eixo de apropriação da cidade e o exercício do direito à cidade como fundamento do exercício político da cidadania. O trabalho sócio-educativo, nesse sentido, permeia as atividades, politizando a dimensão das oportunidades, referência central do projeto. ${ }^{2}$

2 A proposta pedagógica e a elaboração do projeto assim como as diretrizes dada pelo Polo de Suporte às Políticas de Proteção a família, infância e juventude, não nos agradou. Trouxemos discordâncias no aspecto teleológico e metodológico desse projeto, porém esse embate foi feito de forma amena para que isso não acarretasse uma possível perda de um importante espaço de contradição. Decidimos então trabalharmos esses apontamentos contrários, no interior de nossa oficina $(\mathrm{EF})$, voltados em nosso método. 
Com o desenrolar do projeto alguns jovens abandonaram as atividades por diversos motivos, desde os mais objetivos, tais como ter que trabalhar no horário das oficinas até os que resultaram da falta de motivação com o projeto.

Iremos nos ater agora somente na oficina de Educação Física que se difere das outras não somente pelo conteúdo mas principalmente nas direções a serem seguidas. Desde o começo sabíamos dos desafios que teríamos pela frente, especialmente no que diz respeito a superar as representaçôes tradicionais que permeiam o senso comum sobre a Educação Física: sua identificação com o esporte competitivo, a busca de formação e seleção de talentos esportivos, a prática de atividades sem reflexão, a ênfase no treinamento físico e técnico através de repetições, etc. Assim, na tentativa de basear nossa ação para enfrentar e superar tais representações, organizamos um grupo de estudos com alunos da Faculdade de Educação Física e Desportos (FAEFID) e definimos as diretrizes teórico-metodológicas do trabalho que desenvolveríamos com esses jovens.

Proporcionar um entendimento mais amplo e crítico do mundo das atividades físicas, do esporte e do lazer é ainda mais valioso, se levarmos em consideração a condição social dos jovens inscritos na oficina. De acordo com os dados fornecidos pelo relatório das ações do projeto em 2004 (CASSAB; MENDES; PORTELLA, 2005), quanto à renda familiar tem-se que 48,4\% possuem renda até dois salários mínimos, 38,7\% de dois a quatro salários, enquanto que $12,9 \%$ possuem renda familiar de quatro salários mínimos ou mais. A renda per capita média entre essas famílias é de R $\$ 133,00$. E quanto à ocupação profissional dos pais desses jovens observa-se que as mães apresentam idade que variam de 31 a 63 anos, 48,3\% desenvolvem atividade de doméstica/ diarista, 29\% são "do lar", 6,5\% estão desempregadas, enquanto que $16,2 \%$ possuem como ocupação profissional atividades como balconista, acompanhante, cozinheira, etc. Quanto aos pais tem-se que entre $47,9 \%$ há pedreiros, eletricistas, mecânicos, comerciantes e técnico em enfermagem; entre 13,9\% encontram-se aqueles que 
desempenham atividades de carpinteiro, porteiro e jardineiro; 8,7\% dos pais encontram-se desempregados e $26,1 \%$ estão aposentados. Portanto, estamos diante de jovens da classe trabalhadora e nossa proposta visa, além de ampliar sua vivência no mundo das atividades físicas, esportivas e de lazer, fazer com que eles compreendam criticamente o processo de injustiça e desigualdade ao qual estão historicamente submetidos.

Buscamos explorar as possibilidades que esse campo proporciona em termos de uma ação educativa e crítico-pedagógica. Para nós, "a admissão da importância do lazer na vida moderna, significa considerá-lo um tempo privilegiado para a vivência de valores que contribuam para mudanças de ordem moral e cultural" (MARCELLINO, 1996, p. 15).

Atuar nessa perspectiva significa buscar superar o modelo tradicional que tem baseado o trabalho com a Educação Física em seus diversos campos de atuação, especialmente o escolar e o lazer. Apoiadas no paradigma da aptidão física, as práticas corporais são reduzidas ao seu aspecto biológico, à ênfase no ensino da técnica, à preparação física, ao fazer pelo fazer e ao desenvolvimento de valores como a competitividade, a hierarquia e a obediência.

Os jovens devem aprender e apreender o universo das atividades físicas, não apenas sob o enfoque do aprendizado para a prática, mas também para o consumo crítico dessas atividades.

A formulação original da proposta crítico-superadora tem como local de produção e intervenção a instituição escolar. No entanto, tal pensamento que critica o modelo tradicional de Educação Física e lança bases teórico-metodológicas para fundamentar sua superação pode inspirar outros setores como o campo do lazer. ${ }^{3}$

3 Cabe aqui uma questão importante, específica sobre esses jovens: como consideramos o tempo que estes jovens passam conosco na UFJF? Lazer ou trabalho? Arriscamos a dizer que este é um tempo de semilazer, ou seja, mais do que qualquer outro interesse, aquele que traz estes jovens a UFJF é a satisfação pessoal alcançada com as diversas atividades programadas. 
O lazer pode ser definido como o tempo que resta das obrigações de trabalho, familiares, religiosas e fisiológicas, disponível para a fruição e vivência de atividades artísticas, intelectuais, físicas, manuais, sociais e turísticas (DUMAZEDIER, 1980). É, portanto, um tempo onde a cultura é vivenciada. Um tempo em que certas condiçốes, como a de classe social, por exemplo, podem ter repercussóes limitadoras. E esse problema afeta os jovens inscritos no projeto como veremos mais à frente no texto.

Valendo-nos da perspectiva de Marcellino (1987), consideramos o lazer como campo de intervenção social que possui um duplo aspecto educativo, ou seja, o lazer pode ser objeto e veículo de educação. E está aqui a base fundamental para nossa ação.

Tratando-se do lazer como veículo de educação (a educação pelo lazer) é necessário considerar seu potencial para o desenvolvimento das consciências crítica desses jovens. As atividades que propomos no projeto, ainda limitadas aos interesses físico-esportivos, visam contribuir para o prazer propiciado pela prática das mesmas, para o desenvolvimento de valores como a solidariedade e a cooperação, como também para a compreensão crítica da realidade social.

Já o lazer enquanto objeto de educação, ou seja, a educação para o lazer: visa demonstrar a sua importância, esclarecer sobre seus significados, ampliar o conhecimento dos envolvidos sobre as diferentes possibilidades de ocupação do tempo disponível, derrubar barreiras impostas por preconceitos e estereótipos e alimentar o espírito crítico com relação à ação da indústria cultural.

Nos primeiros contatos com os jovens inscritos no projeto buscamos conhecer suas experiências anteriores com a Educação Física e o lazer e concluímos que: (a) o esporte competitivo é a base de suas práticas anteriores; (b) suas vivências são limitadas as atividades esportivas tradicionais; (c) suas experiências são marcadas por preconceitos e estereótipos, especialmente aqueles relacionados à categoria gênero; $\mathrm{e}(\mathrm{d})$ sua condição de classe funciona como barreira à vivência de atividades culturais na cidade. 
Também questionamos os jovens sobre suas expectativas com relação à participação da Educação Física no projeto e registramos alguns depoimentos:

- "Eu quero fazer futebol, natação, ginástica, dança e se tivesse capoeira seria uma boa".

- "Na área da Educação Física espero que tenham poucas aulas teóricas e mais aulas práticas".

- "Eu quero praticar vários esportes junto com meus amigos".

- "Acho que a Educação Física é importante hoje em dia, pois pode tirar jovens da rua e divertir quem rala a semana toda".

- "Eu espero aprender coisas novas, ter oportunidades. Poder

- fazer uma faculdade aqui mais pra frente. Para mim a Educação Física tem grande importância”.

Conhecer as experiências dos jovens com a Educação Física e suas expectativas com relação a nossa atuação no projeto foi de fundamental importância para estabelecermos os objetivos específicos de nossa ação, bem como as estratégias metodológicas a serem utilizadas.

Constatamos que suas experiências com as atividades físicas sistematizadas eram restritas às modalidades esportivas tradicionais com caráter competitivo. Sendo assim, nosso principal objetivo foi ampliar as vivências dos alunos no que diz respeito às práticas corporais através do trabalho com a natação, os jogos e brincadeiras, a ginástica artística, a ginástica rítmica desportiva e outros. Questões interessantes foram trabalhadas a partir destes conteúdos, como veremos a seguir.

Logo no primeiro dia de nossa ação no projeto, os alunos foram apresentados às instalações da FAEFID. A piscina foi o local mais festejado e logo solicitaram que a primeira atividade fosse a natação. Atendemos o pedido. Trabalhamos com o conceito do que é "nadar", ou seja, deslocar-se no meio líquido através de variadas formas e gestos que necessariamente não são aqueles utilizados nos "nados" da natação de alto nível. Os alunos 
compreenderam que a técnica não é algo dado, imutável, mas que pode ser reconstruída de acordo com os objetivos e as necessidades de cada um.

O trabalho com a unidade "jogos e brincadeiras" foi orientado no sentido de que os alunos trariam para a aula atividades de sua própria escolha. Eles foram divididos em grupos e cada grupo deveria organizar a sua atividade para o restante da turma. Buscamos explorar seu potencial criativo, sua capacidade de organização e sua autonomia. No nosso entender o jogo deve ser uma atividade que trata o presente, não tendo compromisso com nada fora dele mesmo (FREIRE, 2003), no entanto, não podemos achar que o ato de brincar não é um ato que educa, por entendermos esse momento como "não-sério", afinal ao brincarmos desenvolvemos o pensar, o criar, a autocrítica, reconhecimento de si, entre outros.

Perceber que o brincar é importante na vida das pessoas não é o bastante para que ele seja reconhecido pela sociedade, falta ainda na nossa cultura o reconhecimento do ócio e da sua necessidade para o desenvolvimento do ser humano.

A ginástica artística e a ginástica rítmica desportiva foram escolhidas propositalmente com o objetivo de flagrar no grupo manifestações de preconceito e estereótipo com relação ao gênero. Historicamente vivemos uma "Pedagogia da sexualidade":

Ali se aprende uma linguagem socialmente situada, que diz sobre o que falar e sobre o que silenciar, o que mostrar e o que se esconder, quem pode falar e quem deve ser silenciado. Marcas de gênero, classe, raça interferem profundamente na demarcação desses arranjos (LOURO, 1999, p. 33).

Foram apresentados os principais elementos e aparelhos das ginásticas, bem como exercícios básicos. Durante as atividades, vários alunos homens recusaram-se a participar e comentários do tipo "Isto é coisa de mulher!" foram comuns. Na aula seguinte, trabalhamos com o filme "Billy Elliot". 4

4 Produção inglesa do diretor Stephen Daldry no ano de 2000. 
$\mathrm{O}$ ator Jamie Bell interpreta um garoto de 11 anos que vive numa pequena cidade da Inglaterra, onde o principal meio de sustento são as minas da cidade. Obrigado pelo pai a treinar boxe, Billy fica fascinado com a magia do balé, ao qual tem contato através de aulas de dança clássica que são realizadas na mesma academia onde pratica boxe. Incentivado pela professora de balé (Julie Walters), que vê em Billy um talento nato para a dança, ele resolve então largar as luvas de boxe e se dedicar à dança, mesmo tendo que enfrentar a contrariedade de seu irmão e de seu pai à nova atividade.

Utilizamos o filme para discutir os estereótipos e preconceitos de gênero que permeiam a prática de atividades físicas. Houve um intenso debate entre os alunos e a participação masculina nas atividades aumentou.

Fizemos uma apresentação na XX Mostra de Ginástica e Arte Corporal, que acontece a cada semestre na Faculdade de Educação Física e Desportos da UFJF, onde acadêmicos e alunos de extensão tem a oportunidade de mostrar para a comunidade universitária e para a população em geral um pouco do que foi aprendido e, para nós, uma oportunidade de levantar questões como a importância de saber trabalhar em grupo, ouvir as opiniões do outro, respeitar as limitaçôes do colega, cooperar com o grupo, controlar a ansiedade e superar a timidez.

Quando sugerimos aos alunos que produzíssemos um trabalho para esse evento, ficaram um pouco assustados com a idéia de se apresentarem em público, mas levamos alguns vídeos de mostras anteriores, discutimos como seria essa apresentação, e a maioria aceitou o desafio.

Alguns alunos ainda ofereceram resistência: “... eu não sou artista, não quero pagar esse mico, só quero jogar bola”. ${ }^{5}$

O início do trabalho foi complicado, mas ao longo das discussões os alunos foram se envolvendo e o resultado foi surpreendente. Esses jovens que não estavam habituados a esse tipo de

5 Frase que foi amplamente discutida na avaliação. 
situação subiram ao palco e encantaram o público com uma coreografia de aproximadamente quinze minutos, que misturava, de forma bastante original e alegre, os conteúdos trabalhados até o momento com aqueles que fazem parte da sua cultura e do seu cotidiano. Eles se dividiram e apresentaram, de acordo com seus interesses, um mix de funk, hip-hop, forró, ginástica rítmica desportiva, diversos esportes, ginástica artística e capoeira. Aqueles que não se sentiram à vontade para se apresentar no palco se dispuseram a atuar nos bastidores.

Em seguida trabalhamos o conteúdo atletismo, que embora englobe movimentos naturais como correr, saltar e arremessar, muitas vezes o praticante não consegue perceber esses movimentos no seu dia a dia, pois o processo de esportivização dessa prática passa a exigir local, implementos e equipamentos próprios dificultando o acesso a essa cultura.

Foi trabalhado o histórico da modalidade, eles tiveram a oportunidade de conhecer uma pista de atletismo com seus diversos setores, vivenciar os saltos verticais e horizontais, os arremessos e lançamentos e as provas de pista. Utilizamos deste conteúdo como uma primeira tentativa mais consistente de aproximar esses jovens de nossa metodologia, sendo assim as discussões se deram em torno do que vem a ser a chamada "cultura corporal" de movimento descrita pelo Coletivo de Autores (1992), assim como os valores degradantes tais como a competitividade, a hierarquia, a performance, o dopping, tidos como valores da cultura do modo de produção capitalista. Para tanto fizemos questão de evidenciar e assemelhar a competição no âmbito do lazer e do esporte com a competição que se dá no dia a dia, e a utilização do esporte com o intuito de educar os futuros trabalhadores para as competências do mercado.

Apesar do tempo do lazer e do esporte ser um tempo, para nós, que deveria ser livre do trabalho, ou seja, um tempo onde se desenvolveria a autonomia, a criatividade, o lúdico, esse vem sendo ressignificado para a estruturação do consenso em torno dos interesses dominantes. 
Com o conteúdo basquetebol trabalhamos os principais fundamentos, o jogo e as possibilidades para aqueles que não são tão altos e nem tão fortes, para isso utilizamos da construção coletiva de novas regras, assim como a adaptação do espaço onde se desenvolveu a prática. Com isso acreditamos, novamente, que desenvolvemos a capacidade dos alunos de perceberem que as técnicas e as regras não são imutáveis.

Em seguida solicitamos que eles desenvolvessem uma pesquisa sobre o projeto "Basquetebol de Rua", desenvolvido pela Central Única das Favelas (CUFA), no que tange sua metodologia, prática, público-alvo e organização, o que nos possibilitou discutir o que vem a ser um projeto social, inclusive o próprio Território de Oportunidades. Assistencialismo, "cinturão social", violência, drogas e ocupação do tempo foram prerrogativas para entendermos os reais interesses de alguns desses projetos. Para tanto utilizamos textos seguidos de intenso debate.

O próximo conteúdo que abordamos em nossa oficina foi o futebol. Antes de partirmos para a descrição das aulas, faz-se necessário algumas reflexões para compreendermos a importância dessa modalidade em nosso país. O Brasil é considerado o país do futebol, tendo sua programação esportiva voltada em quase sua totalidade para assuntos relacionados a essa modalidade. Pouquíssimas vezes podemos assistir outros esportes. A possibilidade ainda que remota de se ganhar salários monstruosos atrai milhares de crianças e jovens para a prática dessa modalidade, nem sempre com o intuito de brincar, mas com caráter de ascensão social e por muitos é tido como o "ópio do povo". Não pretendemos aqui esgotar o assunto, pois isso demandaria amplos estudos mais aprofundados.

Tão importante quanto o apresentado acima são as questões relacionadas ao gênero, que no contexto futebolístico advém de uma cultura machista, mas que vem perdendo força com o que chamamos de um misto entre a luta feminista e a percepção dos interesses capitalistas em relação à possibilidade de um novo nicho de lucro: a mulher!

Trabalhamos esse conteúdo justamente no momento em que os olhares do mundo todo estavam voltados para o futebol: 
a Copa do Mundo! Escolhemos essa época para que as contradições entre o futebol, como componente da cultura corporal e o futebol fruto da mídia e do mercado ficassem mais evidentes.

Iniciamos esse conteúdo com a história do futebol no mundo e no Brasil, trabalhando através de pequenos jogos o futebol, desde suas origens até a maneira como ele éjogado atualmente, contando com a participação dos meninos e das meninas. Como outro recurso pedagógico fizemos a apresentação de um DVD, que tratou a história do futebol. Em seguida partimos para uma discussão de gênero no futebol, com o texto: Pode a mulher jogar futebol? (GOELLNER, 2000). Para tanto dividimos a turma em dois grupos, um grupo defenderia a presença da mulher e o outro seria de posição contrária, simulando um tribunal.

Para finalizar esse conteúdo trabalhamos a questão da mídia e os jogadores enquanto mercadorias e enquanto vitrines para estimular o consumo e valorizar produtos. Nessa aula os alunos criaram um teatro para reproduzir essas situaçóes.

Mais uma vez trabalhamos a questão do gênero, ${ }^{6}$ só que agora com o intuito de denunciar e de contar historicamente o processo de exclusão que a mulher vem sofrendo ao longo do tempo e não mais com o sentido que trabalhamos inicialmente com o filme Billy Elliot, ou seja, a tentativa de desmistificar o que é próprio de um sexo ou outro na "cultura corporal".

A partir do conteúdo voleibol pudemos entrar no que chamamos de segunda aproximação metodológica. É importante ressaltar que o conceito metodológico se faz presente em todas as atividades propostas, pois a metodologia ainda que não explicitada é algo que não tem como ser desvinculada da prática. Esses momentos foram escolhidos estrategicamente para dar corpo às práticas desenvolvidas sob a perspectiva crítico-superadora. Sabemos que esses alunos estão passando por um processo de desconstrução

6 Essa temática por ter sido recorrente nas aulas, faz saber: Entendemos que a discussão de gênero torna-se um fenômeno importante para as aulas de Educação Física, no entanto essas discussões não podem assumir puramente o caráter de afirmação, elas devem ser analisadas prioritariamente a partir das relações sociais e da luta de classes. 
de anos de prática alienante, portanto se torna ainda mais importante o entendimento de como romper com essas barreiras, e mais: os motivos pelos quais utilizamos nas nossas aulas uma metodologia critica e não reprodutivista. Nesse momento fizemos a confrontação da realidade vivida por esses jovens com aqueles que são filhos da burguesia, tal ação os levou momentaneamente a um choque e em seguida uma sadia indignação. Para nós o exercício de chocá-los tem sua relevância em uma possível tentativa de torná-los militantes de seus interesses de classe ainda mais quando se trata de jovens com idade de 15 a 18 anos.

Trabalhamos a história do voleibol, evolução das regras em função da mídia, buscando a espetacularização e dinamismo dos jogos.

Foi levantado ainda que empiricamente, a questão dos meninos que jogam voleibol serem afeminados.

Demos inicio a montagem de nossa segunda coreografia para a Mostra de Ginástica e arte corporal da FAEFID, que teve como tema: Corpo, Cultura e Mídia. Após debatermos o tema, partimos para a construção da coreografia que apresentava um pouco do basquete, voleibol, ginástica artística, ginástica rítmica e desportiva, capoeira e hip-hop. No final dessa apresentação os jovens cantaram a música "Comida", dos Titãs. A escolha partiu dos próprios alunos, pois viam nela uma critica social: "a gente não quer só comida, a gente quer comida, diversão e arte...”.

No momento de construção, apresentação e avaliação da mostra, pudemos evidenciar com mais clareza algo que estávamos percebendo no grupo. Com o passar do tempo, os "grupinhos" foram se formando e as diferenças aflorando, o que os levaram a entrar diversas vezes em conflito, dificultando a construção no coletivo. Essa contradição, que emergiu no interior do projeto, a priori pareceu negativa mas com o tempo, essa, serviu para que o jovens reconhecessem a importância de se manterem coesos.

Uma tentativa de solucionar esse problema foi conversar com os alunos, onde falamos um pouco das diferenças, que apesar delas existirem não poderiam ser algo que viesse a atrapalhar o 
andamento do projeto, mas pelo contrário, é a partir das diferenças que podemos avançar, enquanto grupo.

Após conversarmos com Juliana Thimóteo N. Mendes, assistente social, ela caracterizou o problema como não sendo apenas na Educação Física, mas em todas as outras oficinas, acreditando que esses jovens tiveram sua autoestima muito trabalhada, o que veio a ocasionar um inchaço no ego. É bom ressaltarmos que essa análise, ainda que relevante, talvez não tenha sido compartilhada na integra entre nós professores.

Prosseguimos nosso trabalho, agora com o tema Cultura. Para tanto exploramos os conhecimentos prévios dos alunos e construímos um conceito para esse termo a partir das palavras levantadas por eles: "estilo da pessoa, comida, vestimenta, religião, arte, música, esporte, tradições, patrimônio”. A partir daí falamos sobre a cultura ser algo vivo, construído historicamente pelos sujeitos, influenciando e sendo influenciada por eles. Que somos seres humanos capazes de criar, reinventar e construir cultura. Utilizamos o corpo para criar novos movimentos, rompendo com a cultura de massa, desmistificando a idéia de que o movimento diferente de uma maioria é um movimento que não é belo e que não traz valores embutidos.

Dividimos os alunos em pequenos grupos e propusemos que eles montassem uma pequena coreografia, que ao final foi apresentada como sendo uma única. Foi ótimo, pois os alunos puderam perceber que o que a princípio poderia ser um problema, a diferença, no final resultou numa interessante apresentação de diferentes movimentos entre eles.

O próximo passo foi convidar um grupo que representasse uma cultura popular, chamamos então o grupo Posse Zumbi dos Palmares, que funciona na cidade de Juiz de Fora e trabalha com os elementos do hip-hop. O grupo apresentou a origem do hip-hop e os cinco elementos que compóem a sua prática: break, grafite, rap, DJ e informação. Na prática os alunos puderam evidenciar alguns movimentos do break e a arte do grafite. 
O caráter reivindicatório dessa cultura para nós foi de extrema relevância, pois assim pudemos alimentar o que chamamos de espírito crítico nesses jovens.

Prosseguimos com o conteúdo capoeira, escolhida por ser uma possibilidade de solidificação de tudo o que foi trabalhado até aqui, pois acreditamos que ela nasce de um movimento de libertação dos negros e que historicamente vem sendo modificada e ampliada em seus sentidos, portanto começamos pela história da capoeira, onde o enfoque se deu na colonização e escravização do negro.

Convidamos os professores Thiago Barreto e Lionel Rodrigues para trabalhar esse conteúdo com os alunos. O primeiro trabalhou a possibilidade de se praticar a capoeira de forma mais lúdica, ou seja, apresentou os movimentos de capoeira de diversas maneiras, essencialmente através de brincadeiras. $\mathrm{O}$ segundo trabalhou mais a parte técnica dos movimentos e apresentou os instrumentos musicais que acompanham essa prática. Ambos abordaram a questão da esportivização desse conteúdo, que resultaria numa possível perda da identidade cultural. A capoeira, se não entendida no âmbito das correlações de força que se deram no período de escravização do negro, passa a ser uma prática estanque da reflexão histórica dessa manifestação cultural, tornando-se o movimentar pelo movimentar.

É importante chamar a atenção para as confederações que envolvem as práticas corporais, pois as mesmas contribuem para a padronização dos movimentos. Do mesmo modo, as ingerências do Conselho Nacional de Educação Física (CONFEF) na "cultura corporal" vêm contribuindo para o empobrecimento e para mercadorização desses conteúdos. Seria preciso tratar esse assunto com mais especificidade, o que não é objetivo deste artigo.

Para finalizar o projeto, trabalhamos com o conteúdo ginástica de academia, principalmente por ser esse conteúdo de difícil acesso aos filhos da classe trabalhadora, por serem controlados por grupos privatistas e que muitas vezes é trabalhado na perspectiva do fazer pelo fazer, relegando seu caráter educativo.

Os alunos puderam ter contato com essa prática através de uma aula de ginástica localizada e uma aula de hidroginástica. 
O conhecimento educativo ligado a essa prática diz respeito aos conhecimentos sobre o corpo, sua anatomia, fisiologia, efeitos provocados pelo exercício durante e após a prática.

A atividade física como gerenciadora de possíveis complicaçôes na saúde vem desobrigando o Estado em uma de suas atribuições básicas: a saúde, que para nós deve ser algo acessível a todos, sem distinção de classe.

Trabalhamos até aqui com a descrição de nossas aulas realizadas no decorrer do projeto. E bom deixar claro que de forma nenhuma pretendemos, com esse artigo, deixar uma receita, ou seja, algo que deva ser seguido à risca, no entanto, faz-se importante essa descrição por trazer com ela pontos interessantes a serem trabalhados nas aulas de Educação Física. Acreditamos que a prática da docência acima de tudo deve primar pela subjetividade que os diferentes alunos trazem consigo. Igualmente é necessário de nossa parte a concordância com o possível leitor que queira indagar sobre as possibilidades objetivas e, portanto, reais de se trabalhar esses conteúdos no interior das estruturas físicas oferecidas pelas nossas escolas públicas. Sabemos da precariedade dessas instituições e se comparadas a Faculdade de Educação Física da UFJF, que também são precárias, isso se torna ainda mais gritante, porém acreditamos que a ausência de meios que permitam o acesso da classe trabalhadora às culturas corporais devem ser trabalhados no seu aspecto contraditório. Uma possível mediação para isso gira em torno das políticas que envolvem o financiamento do esporte de alto rendimento advindas do Ministério dos Esportes.

Para avaliarmos esses jovens e os impactos dessa metodologia em suas vidas assim como o conhecimento adquirido durante esses dois anos de convivência decidimos elaborar algumas questôes para serem comentadas e/ou respondidas pelos alunos. Essas afirmações, indagações surgiram a partir da leitura dos objetivos traçados nas aulas descritas acima:

- Quais as atividades da chamada Cultura Corporal você pôde conhecer / vivenciar a partir do projeto?

- Pode a mulher jogar futebol? 
- As aulas de Educação Física são o meio de desenvolver no aluno o ensino da técnica, preparação física e o desenvolvimento de valores como obediência, hierarquia e competitividade.

- Brancos praticam natação e negros atletismo!

- Relacione a sua Educação Física escolar com o projeto.

- Comentem em relação a esportivização da capoeira e as implicações nessa cultura.

- Comentem projeto enquanto política social.

- A mídia não tem nada a ver com a cultura!

- Cultura é teatro!

- Qualquer pessoa pode se tornar um Ronaldinho desde que se esforce pra isso...

Cada aluno sorteava aleatoriamente uma questão, lia, comentava e em seguida abríamos para uma discussão coletiva. Portanto, procuramos avaliar os alunos por meio dos seus discursos.

$\mathrm{O}$ resultado dessa avaliação nos permite afirmar que houve uma mudança considerável na forma com que esses alunos passaram a compreender a Educação Física e grande parte das mediações / contradições que perpassam os conteúdos trabalhados. Isso se torna mais evidente se compararmos as falas iniciais desses alunos, no momento em que chegaram ao projeto, com as elaboraçôes finais presentes na avaliação.

A título de ilustração podemos citar a frase que trouxemos no texto para elucidar a representação que os alunos tinham sobre a Educação Física, proferida por um aluno no primeiro dia de aula: "Acho que a Educação Física é importante hoje em dia, pois pode tirar jovens da rua e divertir quem rala a semana toda”. Já na atividade de avaliação o mesmo aluno afirma em uma de suas intervenções: "A Educação Física é muito importante para nossas vidas, mas ela sozinha não é capaz de resolver todos os nossos problemas”. Tal afirmação demonstra um amadurecimento assim como uma ampliação do modo como que esse aluno percebia as relações sociais e o mundo. 


\section{Referências}

ANDERSON, Perry. Balanço do Neoliberalismo. In: SADER, Emir; GENTILI, Pablo (Orgs.). Pós-Neoliberalismo: As políticas sociais e o Estado democrático. 5 ed. Rio de Janeiro: Paz e Terra, 1995.

ANTUNES, R. Os sentidos do trabalho: ensaio sobre a afirmação e a negação do trabalho. São Paulo: Boitempo Editorial, 1999.

CASSAB, Maria Aparecida Tardin; MENDES, Juliana T. N.; PORTELLA, Maria Carolina Ribeiro. Projeto UFJF - Território de Oportunidades - Relatório de Atividades - 2004. Juiz de Fora: UFJF, 2005.

COLETIVO DE AUTORES. Metodologia do Ensino da Educação Física. Campinas: Cortez, 1992.

DUMAZEDIER.J. Valores e conteúdos culturais do lazer. São Paulo: SESC, 1980.

FREIRE, J. B. Educação como Prática Corporal. São Paulo: Scipione, 2003.

FRIGOTTO, Gaudêncio. O enfoque da dialética materialista histórica na pesquisa educacional. In: FAZENDA, Ivani (Org.). Metodologia da pesquisa educacional. São Paulo: Cortez. 1989.

. Fundamentos científicos e técnicos da relação trabalho e educação no Brasil de hoje. In: LIMA, J. C. F, NEVES W. L. (Orgs.). Fundamentos da educação escolar do Brasil contemporáneo. Rio de Janeiro. FIOCRUZ, 2006.

GENTILI, Pablo. Educar para o desemprego a desintegração da promessa integradora. In: FRIGOTTO, Gaudêncio (Org.). Educação e Crise do trabalho: perspectivas de final de século. Petrópolis: Vozes, 1998.

GHIRALDELLI Jr., Paulo. Educação Física Progressista: A Pedagogia Crítico-Social dos Conteúdos e a Educação Física. São Paulo: Loyola, 1992.

GOELLNER, Silvana V. Pode a mulher a praticar futebol? In: CARRANO, Paulo C. (Org.). Futebol: paixão e política. Rio de Janeiro: DP\&A, p. 79-93, 2000.

LEHER, Roberto. O Bird e as Reformas Neoliberais na Educação. PUC Viva Revista. n. 5, jun. 1999. 
LOURO, Guacira Lopes. Pedagogias da Sexualidade. In: LOURO, Guacira (Org.). O corpo educado-Pedagogias da sexualidade. Belo Horizonte: Autêntica, p. 7-34, 1999.

MACHADO, L. Politécnica, escola unitária e trabalho. São Paulo, Cortez, 1989.

MARCELLINO, Nelson Carvalho. Lazer e Educação. Campinas: Papirus, 1987.

Associados, 1996.

. Estudos do lazer: uma introdução. Campinas: Autores

MARX, Karl. O capital: crítica da economia política. Livro 1, v. 1, 2. ed. São Paulo: Nova Cultural, 1985.

MARX, Karl; ENGELS, Friedrich. A ideologia alemã. São Paulo: Martins Fontes, 1989.

SAVIANI, D. Pedagogia histórico-critica: primeiras aproximações. Campinas: Autores Associados, 1997.

SOARES, C. Educação Física: raízes européias e Brasil. Campinas: Autores Associados, 1994. 